\title{
Los disfraces de la peligrosidad
}

\section{(La pena del delito común contra la propiedad)}

\section{Eugenio Raúl Zaffaroni}

1. Objeto e hipótesis. La culpabilidad es el conectivo entre el injusto y la pena y, por ende, el concepto más esencialmente penal de la teoría del delito, donde ninguna otra rama del derecho puede acudir en ayuda del penalista, salvo el constitucional, que las nutre a todas.

En los últimos años, si bien se afirma casi con unanimidad que la pena debe tener la medida de la culpabilidad, el concepto de culpabilidad se dispersa en múltiples acepciones, lo que muestra el desconcierto de la doctrina penal.

No pretendemos en el reducido espacio de una exposición detallar estos ensayos conceptuales, sino sólo sobrevolarlos con el objeto de verificar las hipótesis de que todos ellos configuran diferentes esfuerzos constructivos que tienden (a) a disfrazar de culpablidad a la vieja peligrosidad positivista (b) o a conceptos con pareja funcionalidad policial; (c) constatar que esta discusión adquiere relevancia práctica casi por entero en los casos de reiteración de delitos contra la propiedad. Por último, (d) nos planteamos si es posible compatibilizar la culpabilidad con le ética, al menos en cierta medida.

2. La cuestión proviene de la Edad Media. La pena conforme a un reproche personal formulado a un humano (persona) con autonomía moral, es una idea que se remonta a los primeros penalistas (glosadores y prácticos), en contradicción con los demonólogos, que reclamaban penas duras para las brujas por su peligrosidad policial, pese a que según la misoginia de la época, que las consideraba menos inteligentes que el hombre, merecían menor reproche. Por ende, la contraposición de culpabilidad y peligrosidad no es nada nuevo, sino casi milenario. 
3. El positivismo retoma la tesis de los demonólogos. Desde fines del siglo XIX y hasta bien entrado el siglo pasado imperaba el positivismo penal, resultante de la coalición de médicos y policías, en el paradigma del reduccionismo biologista en versión spenceriana o sea, del racismo colonialista, para el cual los delincuentes eran seres inferiores parecidos a los colonizados. La pena debía ser medida por su proclividad al delito, llamada peligrosidad, fijada por sus médicos y jueces con neto criterio de orden policial y moralino, propio de la burguesía europea de la Belle Epoque. El juez era una suerte de leucocito que debía eliminar las células infecciosas del cuerpo social.

4. La confusión creada por el positivismo de von Liszt. Cuando la versión italiana del positivismo racista spenceriano (Ferri) se opacó, parte de Europa continental y toda Latinoamérica importaron de Alemania la dogmática penal. El primer autor que trajeron fue Franz von Liszt, que era un positivista matizado (con tintes autoritarios), que medía la pena por peligrosidad para los ocasionales, pero pedía reclusión indeterminada para los habituales, es decir, para ladronzuelos.

Von Liszt creó confusión al llamar culpabilidad a lo que hoy es el tipo subjetivo, como vínculo de causalidad psíquica entre la voluntad y el resultado, en forma de dolo y culpa. Este curioso bautismo escondía que en realidad von Liszt suprimía la culpabilidad de la teoría del delito y dio lugar a la llamada teoría psicológica de la culpabilidad, generadora de disputas interminables, que hoy son curiosidades históricas.

5. Vuelve la forma ética tradicional con Frank. Con la llamada teoría normativa compleja de Frank la culpabilidad recuperó su forma de reproche personal, que lo retomaba de la ética tradicional (Aristóteles, San Agustín, Santo Tomás, Kant, Hegel), como corresponde a su etimología germana (Schuld, deuda, igual que en la versión antigua del Padre Nuestro), aunque conservando en su contenido al dolo y a la culpa, o sea, que en el juicio de reproche incluía también al objeto reprochado. 
En un paso más adelante, Helmuth von Weber, el Graf zu Dohna y especialmente Hans Welzel, transfirieron el dolo y la culpa al injusto, dando lugar a la teoría normativa bomogénea de la culpabilidad.

Desde Frank el derecho penal rescató de la ética tradicional la forma pero no el contenido, porque la selectividad estructural del poder punitivo no es para nada ética. Como es imposible separar radicalmente la forma del contenido, la recuperación de la mera forma chocaba contra la legitimación ética de la selección policial criminalizante.

6. La disfuncionalidad policial de la culpabilidad. La disfuncionalidad policial se manifestaba en que serían menos reprochables los más pobres (menos espacio social) y los habituales y reincidentes (el bábito inclina a la reiteración y requiere un mayor esfuerzo para elegir la conducta conforme a derecho), o sea, que los peligrosos policialmente serían los menos culpables penalmente. Se volvía a plantear el problema que provenía del Medioevo.

7. Se inventa la doble vía: penas por peligrosidad. Al tiempo que se preguntó si el reproche debía ser formulado conforme a la psicología individual o según un estándar de exigibilidad (Freudenthal), se decidió dar refugio a la peligrosidad mediante el cambio de nombre a algunas penas, llamándolas medidas de seguridad (Stooss y sus proyectos suizos), lo que se denunció como embuste de las etiquetas (Kohlrausch).

La peligrosidad, sacada por la puerta de la teoría del delito, volvía por la ventana sobre los no delincuentes (inimputales) y se extendía a los medio delincuentes (semi-imputables), pero como eso no era suficiente conforme a los reclamos policiales, se dispusieron también medidas (penas largas indeterminadas) contra los habituales (proyectos y reforma penal alemana de 1933 y código Rocco de 1930), resucitando las penas de galeras y de relegación francesas e inglesas. Esta es la famosa doble vía, que tanto ha dado que hablar. 


\section{El juez omnipotente: culpabilidad por la conducción} de vida. No conforme con este regreso, se planteó una reformulación del propio concepto de culpabilidad apelando a la misma ética tradicional (Mezger). Así se propuso que el reproche no se limitase al ámbito de decisión para el acto, sino a toda la elección existencial del sujeto, como culpabilidad por la conducción de la vida, generalizando la actio libera in causa conforme a la ética aristotélica, pero olvidando que Aristóteles no estaba limitado por la legalidad típica (que estaba suprimida en ese momento). Se propugnaba de este modo, una suerte de juicio final en la tierra : el juez pasaba a ser un Dios juzgador de toda la vida del ladrón.

9. Culpabilidad de autor y personalidad. Otro de los caminos ensayados, volvía también al derecho penal de autor mediante el reproche a su personalidad o carácter, como otra máscara de la vieja peligrosidad policial: cuanto más inherente a la personalidad era la conducta delictiva, mayor era el reproche que se le formulaba al autor (Sauer). Se llegó a proponer dos culpabilidades: una para reprochar el acto y otra para cuantificar la pena, la primera de acto y la segunda de personalidad (Bockelmann). Hasta hoy se suele sostener una confusa teoría combinatoria de ambas.

10. Etización del derecho penal. Una variable la ofreció la llamada etización moderada del derecho penal, que presume que los tipos penales importan una exigencia ética mínima en la sociedad y, por lo tanto, lo reprochable es la medida en que el sujeto omitió el esfuerzo necesario para vencer las pulsiones a la violación de mandatos éticos elementales (Welzel). Además de otras consideraciones (no todos los delitos obedecen a motivaciones inmorales), es insostenible ante la actual inflación desordenada de tipos penales (cuya banalización abarca conductas que muchas veces nada tienen que ver con la ética) y la obvia violación de la ética por parte del propio poder punitivo, debido a su creciente y ostensible selectividad. 
11. La culpabilidad como ficción necesaria. Ante el avance del fisicalismo en la posguerra y la discusión entre determinismo e indeterminismo (que se pierde en los tiempos), se propuso considerar que la culpabilidad se basa en una ficción necesaria (Roxin), criterio que pasa por alto que ambas son posiciones inverificables (pese a alguna apresurada lectura penal de los aportes de las neurociencias). Además, esta tesis se choca frontalmente con la antropología jurídica constitucional, pues de ella resultaría que la democracia representativa y el Estado de derecho estarían asentados sobre una mera ficción.

\section{Supresión autoritaria de la culpabilidad. El recurso más} extremo para resolver la contradicción de la culpabilidad con las demandas policiales, consistió en prescindir directamente de la culpabilidad, pero por una vía diferente a la de von Liszt.

El más notorio de estos intentos introdujo confusamente la personalidad y el ánimo en el injusto, dando lugar a un derecho penal de voluntad, que persigue como objetivo detectar la disposición enemiga de la sociedad, impuesta por una pseudoética creada por mandato político, para depurarla de sus asociales disfuncionales al sistema comunitario. Conforme a este objetivo, los delitos serían omisiones de cumplimiento de esos mandatos pseudoéticos y, de ese modo, el reproche se instalaba en la antijuridicidad, teniendo como objeto el escaso o nulo ánimo del sujeto para cumplir ese supuesto deber ético comunitario (Dahm y Schaffstein). Se quiso llamar a esto teoría unitaria del delito, pero no fue tal, sino una confusa bipertrofia del injusto penal convertido en derecho penal de voluntad, en base a una radical etización arbitraria de todo el derecho penal.

13. ¿Culpabilidad o punibilidad? En las últimas décadas y conforme a un planteo que toma elementos de la sociología sistémica (Luhmann), los combina con un marcado normativismo y cierra con componentes idealistas (Hegel), al tiempo que rechaza toda verificación empírica, se tiende a combinar y hasta identificar la culpabilidad con la punibilidad, lo que conduce 
a otra forma de suprimir la culpabilidad con su formato ético tradicional. La pena tendría por medida lo que fuese necesario para renormalizar, pero también ratificaría la vigencia de la norma y fomentaría la confianza en el sistema (Jakobs).

\section{Co-culpabilidad como compatibilización con el contenido} ético. En medio de estas disputas, se intentó compatibilizar la forma ética de la culpabilidad con el contenido, relevando la diferencia de espacios sociales en sociedades estratificadas (disparidad de oportunidades). Es la llamada co-culpabilidad (Mit-Schuld que proviene de Marat y del buen juez Magnon), según la cual la sociedad debe cargar con la parte del reproche que le incumbe por haber negado a un sujeto el espacio que dio a otros. Este ensayo de reconciliación ética se receptó tímidamente desde hace casi un siglo en algunos códigos (como el argentino).

\section{En la práctica esta discusión no se refiere a delitos} graves ni muy leves. Si bien en los textos de los penalistas estas discusiones suelen referirse y ejemplificarse con delitos de homicidio, sexuales, seriales, etc., lo cierto es que en la práctica judicial esos crimenes graves nunca fueron un serio problema para los jueces, pues en todos los tiempos ninguno de ellos dudó en habilitar para esos delincuentes patibularios la penas más graves, lo que -con cualquier fundamento teórico- siguen haciendo hasta el presente. Pero tampoco lo son los muy leves, resueltos ahora con probation, condena condicional, etc.

Si los libros acuden a esa ejemplificación aterradora, es porque pasan por alto que el delito en general es una creación de la teoría jurídica que ordena las preguntas acerca de todo hecho típico, a efectos de facilitar a los jueces decisiones racionales, pero ese delito general no existe en la realidad, pues cualquier víctima sabe que no lo es del delito, sino de robo, estafa, lesiones, hurto, daño, etc. En efecto: los tipos del código penal describen hechos de entidad y desvalor social totalmente diferente. Basta pensar que entre una violación y un libramiento de cheque sin provisión de fondos no cabe ninguna comparación en cuanto a 
gravedad, daño físico y psíquico, dolor de la víctima y reprobación social. Se diría que lo único en común es que están descriptos en la misma ley.

\section{El delito reiterado contra la propiedad que colma los} juzgados. Los procesos que cargan los casilleros de todos los juzgados del mundo según señalan todas las estadísticas de sentencias, son por delitos contra la propiedad y, en segundo lugar, a veces por delitos de tenencia y distribución minorista de tóxicos probibidos, que plantean el mismo problema al derecho penal y a los jueces: ¿Qué hacer con los delitos reiterados no muy graves? ¿Qué hacer con los delincuentes no muy dañinos, pero medio tontos y molestos? Estos procesos son el pan nuestro de cada día para cualquier juez de nuestro mundo cultural.

La delincuencia reiterada contra la propiedad (rateros y similares) es la que da lugar al eterno reclamo policial de penas sin proporción con la culpabilidad, frente a lo que el penalismo balbucea, trata de disfrazar a la peligrosidad de culpabilidad o de eliminar la culpabilidad y, en definitiva, cae en la Babel conceptual que acabamos se sobrevolar. Toda esta abigarrada discusión teórica, en definitiva -malgrado los librescos ejemplos patibularios-, en la práctica judicial cobra relevancia casi exclusivamente en la reiteración de delitos contra la propiedad y, dependiendo del país, en delitos leves relacionados a tóxicos.

17. La insuficiencia de la co-culpabilidad. Sin duda que la co-culpabilidad a que hicimos referencia fue un intento de compatibilizar la forma y el contenido ético de la culpabilidad penal, paliando las diferencias de oportunidades determinadas por la pertenencia de clase. Si bien reduce el choque contra la ética al tomar en cuenta la estratificación social, no agota la consideración de toda la vulnerabilidad a la selección criminalizante, que excede la mera pertenencia a una clase social.

En efecto: la criminalización secundaria se distribuye selectivamente por estereotipos, siendo la clase social sólo uno de los componentes del estereotipo del delincuente o del 
peligroso, pero no el único, puesto que éste se completa con labilidad personal, historia de vida, traumas y carencias prematuras, aspecto físico, caracteres étnicos, vestimenta, usos y hábitos adquiridos, orientación e identidad sexual, etc. Todo ese conjunto es lo que determina el estereotipo y la consiguiente vulnerabilidad, configurando el status de estereotipado y, por ende, de vulnerable a la selección criminalizante secundaria.

\section{8. ¿Hasta qué punto es posible etizar al poder punitivo? La} pretensión de etizar el derecho penal es una regresión (más o menos grave según la intensidad) premoderna o pre-iluminista, que quiere reprochar su falla ética al infractor, cuando el propio poder punitivo se comporta faltando a la ética, en razón de su selección por vulnerabilidad (quien hoy está lejos del poder de las corporaciones transnacionales es vulnerable, pero el más cercano es impune). El poder punitivo no está libre de pecado para arrojar la primera piedra, y el derecho penal, justamente, debería esforzarse por etizarlo, y no por introducir confusiones y conceptos que disimulen sus pecados. ¿Pero hasta qué punto es posible una etización del poder punitivo?

El poder punitivo es un becho político cuya selectividad aparece como característica estructural y no accidental. Si bien es posible reducirla, es un sueño cancelarla por completo. Quienes lo han pretendido teóricamente, acabaron por postular su abolición (Hulsman, Christie), lo que importa un nuevo y diferente modelo de sociedad y civilización, o sea, una transformación de la ética mundial que no se logrará desde el limitadísimo objetivo de la dogmática penal. En tanto, el poder punitivo -que goza de muy buena salud- nunca será por entero ético. No obstante, el esfuerzo por reducir la selectividad no sólo es válido, posible y ponderable, sino necesario, puesto que se verifica que existen ejercicios de ese poder cuya selectividad es indignante, pero también otros mucho menos selectivos: no son lo mismo los pecados graves que los leves.

19. Estado y situación de vulnerabilidad. La culpabilidad y el reproche presuponen la autodeterminación de la persona, lo 
que no implica un indeterminismo (o libre albedrío) absoluto, porque no es humano (nadie dispone de un catálogo infinito de posibles conductas en cualquier constelación situacional). Además, semejante imposible bumano implicaría la posibilidad de convertirse en otro y, por ende, no podría responsabilizarse a nadie (la persona que se juzga no sería la misma que cometió el delito). Pero tampoco los seres humanos se vinculan sin presuponer cierto grado de autodeterminación, lo que se verifica incluso en el propio uso del lenguaje. No obstante, los catálogos de posibles conductas son diferentes, según condiciones externas (sociales) y sujetivas (internas), no siendo racional un reproche que ignore estas diferencias de espacios de decisión.

El poder punitivo se expande como una infección, recayendo sobre los más vulnerables: el estafador común que vende la máquina de fabricar billetes a un incauto es criminalizado, pero los responsables de la gran estafa bancaria que determinó la crisis de 2008 y costó a los contribuyentes norteamericanos y europeos un billón de dólares -que podían dedicarse a fines más nobles y útiles-, no fueron criminalizados. Esto obedece a que el primero presenta un alto grado de vulnerabilidad al poder punitivo y los segundos otro muy bajo o nulo.

La vulnerabilidad reconoce un estado y una situación. El estado de vulnerabilidad bajo o alto de una persona es el status de vulnerabilidad al que nos hemos referido antes. No es éticamente correcto reprochar ese estado, cuando vivimos en sociedades estratificadas, prejuiciosas y que padecen injusticias sociales. No obstante, sólo muy pocos entre quienes comparten el mismo estado de vulnerabilidad son criminalizados, o sea que algo deben hacer para alcanzar la concreta situación de vulnerabilidad en que recae sobre ellos el poder punitivo.

20. ¿Qué se debe reprochar? Lo éticamente correcto sería reprochar sólo ese algo que la persona hace para alcanzar la concreta situación de vulnerabilidad, o sea, el esfuerzo que realizó para llegar a la situación de vulnerabilidad. 
Este esfuerzo será mucho mayor cuando la persona parta de un estado muy bajo de vulnerabilidad al poder punitivo (un financista estafador en gran escala, por ejemplo), y será muy bajo cuando parta de un estado de vulnerabilidad relativamente alto (hay personas a las que casi les basta con salir a la calle, por ser portadoras del estereotipo de ladronzuelo).

21. ¿Qué se puede reprochar? Pero el esfuerzo por alcanzar la situación concreta de vulnerabilidad no sólo es lo que debe reprocharse conforme a la ética, sino que también es lo único que se puede reprochar en el plano fáctico. En efecto: el derecho penal se teoriza con el objetivo práctico de que se aplique por los jueces, y éstos tienen un mayor espacio para filtrar menos poder punitivo cuando ese esfuerzo ba sido menor y, por el contrario, carecen del mismo espacio cuando el esfuerzo ba sido mayor.

El juez, en una sociedad más o menos democrática, sin temor a ser estigmatizado y linchado mediáticamente, puede habilitar una pena menor a un ratero, pero no goza del mismo arbitrio de decisión si se trata de un financista al que se le haya retirado la cobertura por violar las reglas vigentes entre los grandes delincuentes de las corporaciones transnacionales, como en el escandaloso caso Bernard Madoff.

Por ende, el reproche al esfuerzo por alcanzar la situación concreta de vulnerabilidad, no sólo es éticamente más correcto, sino que también es lo único posible y exigible en el espacio de decisión de los jueces. Dicho más claramente, el reproche de ese esfuerzo, no sólo es más acorde a la ética, sino que también es lo único posible para los jueces.

22. E1 remanente contrario a la ética. De cualquier manera, no creamos con esto que hemos dado a la culpabilidad un contenido por completo acorde a la ética, porque eso es imposible, dada la antes señalada selectividad estructural del poder punitivo.

En efecto: el financista delincuente seguramente también tuvo colaboradores, instigadores, cómplices y encubridores y casi nunca son todos alcanzados por el poder punitivo. Con toda 
razón podrá dirigirse al juez y decirle ¿Por qué a mí y no a los otros? El derecho penal y el juez sólo podrán responder porque no podemos, no tenemos espacio fáctico ni político para hacer otra cosa.

Hemos salvado a la culpabilidad penal -y a la condición de persona con conciencia moral- dentro de lo posible $\mathrm{y}$, en esos límites proponemos compatibilizar su forma ética con su contenido (avanzando un paso más allá de la co-culpabilidad), mediante la limitación del reproche al esfuerzo personal por alcanzar la situación concreta de vulnerabilidad. El remanente antiético será menor, pero no por eso podremos cancelarlo totalmente, porque lo impide la estructura misma del becho politico del poder punitivo. De cualquier manera, es indispensable reducirlo, aunque sepamos que el remanente siempre será parte inevitable de la mala conciencia del penalista. 